\title{
A Comparative Study of Psychological Distress, Life Satisfaction, Forgiveness and Happiness in Private Sector It Professionals:
} An Exploratory Study

\author{
Monica Sharma ${ }^{1 *}$, Divyanshi Garg${ }^{2}$
}

\section{ABSTRACT}

Working life of an individual takes up a major share of his/her life. The work environment has a pivotal role in the lifestyle of an individual. Hence, it should be nurturing and developing along with the productive standards. The pressures of high performance and monotony can cause negative views among the working people. In the present scenario, the working professionals in the private sectors experience higher levels of psychological distress due to burnout and increased competitiveness. Psychological distresses can consequent in unconstructive views of the environment, others and the self. The concept of life satisfaction, henceforth, comes into focus which in this case, is significantly hindered. Life satisfaction is the subjective assessment of the quality of one's life. Along these lines, conclusive relationship has been established between satisfaction with life and happiness. Moreover, the person with significant levels of life contentment is likely to engage in the act of forgiveness. In Indian context, these hassles might be differing for both the genders. Despite the pressures of daily life and ever demanding role of Indian women in families and their workplace, equilibrium needs to be established where women can play the twin role without compromising on her mental and physical health. This indicates that gender might play a significant role in the experience of Psychological distress, Life Satisfaction, Forgiveness, and Happiness among Males and Females. Based on this premise, the present research attempts to investigate the magnitude of Psychological Distress, Life Satisfaction, Forgiveness, and Happiness among Private Sector IT Professionals. The sample has been segregated on the basis of gender, i.e., males and females. The research intends to find out the discrepancy in the aforesaid variables between the two groups. The sample of 100 IT professionals was surveyed in the ratio of $1: 1$. The research was accomplished using the following tools: General Health Questionnaire (GHQ-12) (Goldberg \& Williams, 1988), The Satisfaction with Life Scale (SwLS) (Diener et al., 1985), Heartland Forgiveness Scale (Snyder, Thompson \& Hoffman, 2005), and Oxford Happiness Questionnaire (Argyle \& Hills, 1989).

Keywords: Psychological Distress, Life Satisfaction, Forgiveness, Happiness

\footnotetext{
${ }^{1}$ Clinical Psychologist and Counsellor,The IIS University, Jaipur, India

${ }^{2}$ M.A. Psychology, IIS University, Jaipur, India

*Responding Author

(C) 2016 I M Sharma, D Garg; licensee IJIP. This is an Open Access Research distributed under the terms of the Creative Commons Attribution License (http://creativecommons.org/licenses/by/2.0), which permits unrestricted use, distribution, and reproduction in any Medium, provided the original work is properly cited.
} 


\section{A Comparative Study of Psychological Distress, Life Satisfaction, Forgiveness and Happiness in Private Sector It Professionals: An Exploratory Study}

Work-related life has always been an essential facet in an individual's life. It is said that one might have spent $35 \%$ of their waking life span at their workplace. Hence, the work environment should be nurturing and developing along with meeting the productivity criteria. People with unproductive working niche can find themselves more prone to psychological distress and the effects of burnout unlike the employees with high levels of job satisfaction. That being said, psychological distress is a term used to describe unpleasant feelings or emotions that interferes with ones level of functioning. Psychological distress can be the resultant of unproductive views of the environment, others and the self. The tremendous burdens of competitiveness and targetachieving performance can cause to form negative belief systems among the working people and elevated levels of burnout. Occupational burnout or job burnout is characterized by exhaustion, lack of enthusiasm and motivation, feelings of ineffectiveness, and also may have the dimension of frustration or cynicism, and as a result reduced efficacy within the workplace. It can be referred to as the "wear and tear of the job".

Mirowsky and Ross (2002) has defined psychological distress as a state of emotional suffering marked by symptoms of depression (e.g., lost interest; sadness; hopelessness) and anxiety (e.g., restlessness; feeling tense). These symptoms may be tied in with somatic complaints (e.g., insomnia; headaches; lack of energy) that vary across cultures (Kleinman 1991, Kirmayer 1989). The etiology of psychological distress at workplace rests on three main theoretical models namely: (a) The Job Demand Control Model, (b) The Demand-Control Model, and (c) The Effort-Reward Imbalance Model.

The Job Demand-Control Model (Karasek, 1979) states that work demands (i.e., workload; time constraints, pace of work; conflicting, emotional and physical demands) exert significant stress on employees and that the level of decision autonomy at work (i.e., high levels of skill utilization and decision authority) moderates the effect of this stress on the mental health of workers. Along the lines of Job Demand-Control Model, the Demand-Control-Support Model (Karasekand Theorell 1990) emphasizes the impact of social support in the workplace on the interaction between decision making authority and work demands. Finally, The Effort-Reward Imbalance Model (Siegrist 1996) highlights the importance of equilibrium between demands and rewards (i.e., wage; social recognition; security; motivation; career perspective) in the experience of work-related psychological stress. According to this model, discrepancy between work demands and work rewards is especially detrimental to the mental health of workers overcommitted to their job. Most empirical studies support the hypothesized influence of high work demands, low decision autonomy, poor social support at work, and minimal rewards on the psychological distress observed in workers (Marchand, Demers, and Durand 2005).

Over commitment to the job yields psychological and cognitive loads on the workers mental health. Organisational demand can increase one's skill utilization and social identification at work. But beyond a certain limit, rise in work demands can foster psychological distress among 


\section{A Comparative Study of Psychological Distress, Life Satisfaction, Forgiveness and Happiness in Private Sector It Professionals: An Exploratory Study}

the workers. Within this perspective, multiple roles within family and work domain can benefit and harm the individuals at the same time. Role conflict between the personal and professional identities can cause employees psychological distress and lower job performance and decreased level of motivation and satisfaction.

Clark (2000) defines work-family balance as "satisfaction and good functioning at work and at home, with a minimum of role conflict". Work life balance is pervasive struggle, experienced by both the genders across their different life-stages and in all types of professions (Darcy et al., 2012; Emslie \&Hunt, 2009). A lack of work-life balance is associated with emotional and behavioral problems such as: anxiety, depression, guilt, decreased productivity, and problematic drinking (Kalliath \& Brough, 2008). It can also lead to increased psychological stress and a sense of burnout (Brummelhuis \& Lippe, 2010). Work-life balance does not occur by completing tasks related to one's various roles but being meaningfully involved in each of the various roles (APA, 2004). This means an individual does not ignore or fail to accomplish responsibilities, but finds a way to maintain significant involvement in friends, leisure activities, community activities, religious activities, and family commitments while still meeting demands of work (APA, 2004).

Traditionally, literature exists on how the struggle of work-life balance has affected women, not men (Burke, 2000). This is because from the early centuries, women have always been working as a home maker whereas men were always seen as the "provider" for the family. However, in the last few years, the notion of the man as the traditional breadwinner or universal worker has begun to change (Halrynjo, 2009; Hochschild, 1997).In this era of fast developing country, not only the females have an increased access to higher education but they are increasingly being employed in the professional settings alongside of men. This has marked an additional source of distress among women, especially those who are married, and/or mothers. The struggle of the women to maintain a desired level of equilibrium in both the familial and professional domains has caused a tremendous pressure on them. Demographic changes is been witnessed in the increasing number of women at the workplace and those belonging to career families. This has generated an increasingly diverse workforce and a greater need of employees to balance their work and non-work lives (Bharat, 2003; Komarraju, 1997; Rajadhyaksha \& Bhatnagar, 2000; Sekharan, 1992). Women, today, are not only made to function in the same working environment as men, but are also exposed to the various multiple role demands and conflicting expectations. "By fulfilling their economic needs, employment has no doubt made women independent with an identifiable social status but it has also made them to juggle into two main domains of life- work and family. They have stepped into work place but the role responsibilities of women still remain the same, i.e., women may be a top executive, still the "nurturing" or "care giving" roles are considered much a part of feminine roles." (Malhotra \& Sachdeva, 2005).Barnett and Baruch (1985) investigated the psychological distress and its association with the balance of rewards and concerns generated by individual women's multiple roles as paid worker, wife and mother. Therefore, there is a need to understand if the work life balance and level of psychological 


\section{A Comparative Study of Psychological Distress, Life Satisfaction, Forgiveness and Happiness in Private Sector It Professionals: An Exploratory Study}

distress can differ according to the gender. With a hike in the level of distress among the genders the concept of life satisfaction and overall sense of happiness and forgiveness is important to discuss as a concern in psychological well-being of the individuals.

Shin \&Johnson (1978) defined life satisfaction as “a global assessment of a person’s quality of life according to his chosen criteria". In other words, it is the degree to which a person optimistically evaluates an overall quality of his/her life as a whole. Life satisfaction is influenced by many constructs.

Happiness, life satisfaction, and well-being are interrelated concepts about one's quality of life (Philips, 2006). Happiness is regarded as a "pleasant emotion"- an affective, brief reaction tied to specific events (Diener et al., 2004). In other words, happiness is "the frequent experience of positive emotions overtime" (Lyubomirsky et al., 2005). Happiness may be defined as the experience of frequent positive affect, infrequent negative affect and an overall sense of satisfaction with life as a whole (Myers \& Diener, 1995). Happiness at workplace is important as happy employees are more sensitive to opportunities in the work environment, more outgoing and helpful to co-workers, and more optimistic and confident - all of which are positive features for the organization. Dr Laurel Edmunds and Jessica Pryce-Jones have researched the issue of happiness at work and from their findings have defined Workplace Happiness as "Happiness at work is about mindfully making the best use of the resources you have, to overcome the challenges you face. Actively relishing the highs and managing the lows will help you maximize your performance and achieve your potential. And this not only builds your happiness but also that of others - who will be affected and energized by what you do.” Workplace happiness depends on many factors as depicted in Figure 1. 


\section{A Comparative Study of Psychological Distress, Life Satisfaction, Forgiveness and Happiness in Private Sector It Professionals: An Exploratory Study}

Figure1. Factors influencing Workplace Happiness

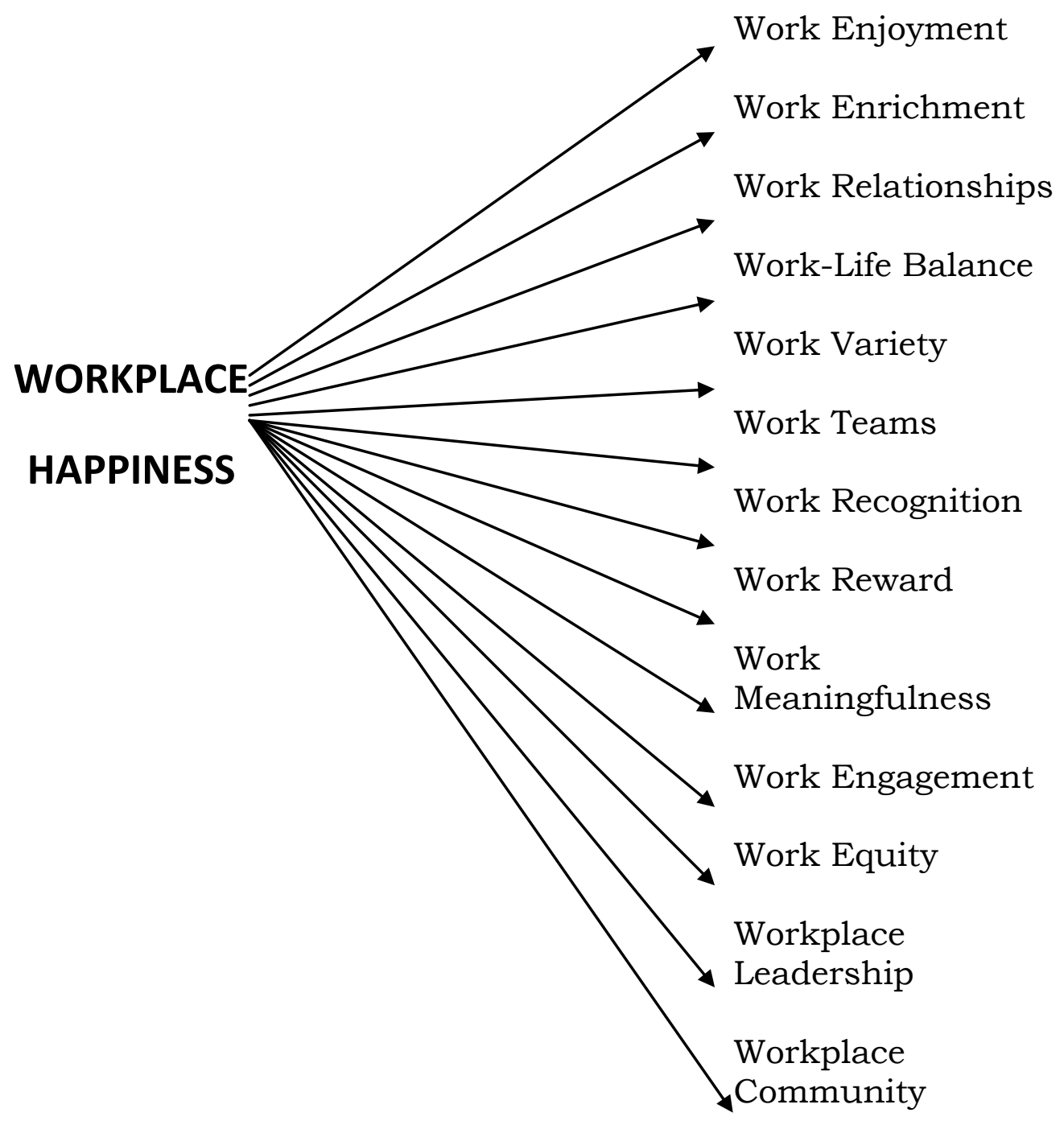

Committing blunders at work is not an exceptional phenomenon. Conflicts between the colleagues or boss and the subordinate are common occurrences for a place that demands dynamic leadership skills. These conflicts hinder the smooth functioning and the sense of happiness among the workers. To restore the feelings of happiness among the employees it is important to discuss the concept of forgiveness and how do both the genders address this issue. Worthington (2005) believes there are two types of forgiveness. "Decisional forgiveness" involves deciding to forgive a personal offense and release all anger and resentful thoughts and feelings towards the person who has wronged you. "Emotional forgiveness" involves substituting the negative emotions with positive feelings like compassion, sympathy, and empathy. Results from research on forgiveness have revealed potential benefits of forgiving. These include 


\section{A Comparative Study of Psychological Distress, Life Satisfaction, Forgiveness and Happiness in Private Sector It Professionals: An Exploratory Study}

benefits to physical health, (Harris \&Thoresen, 2005; Worthington, Witvliet, Pietrini,\& Miller, 2007), mental health (Toussaint \& Webb,2005), and life satisfaction (e.g., Karremans, Van Lange, Ouwerkerk, \& Kluwer, 2003).Gender differences in forgiveness might be expected for several reasons as depicted in Figure 2.

Figure2. Reasons for Gender differences in Forgiveness

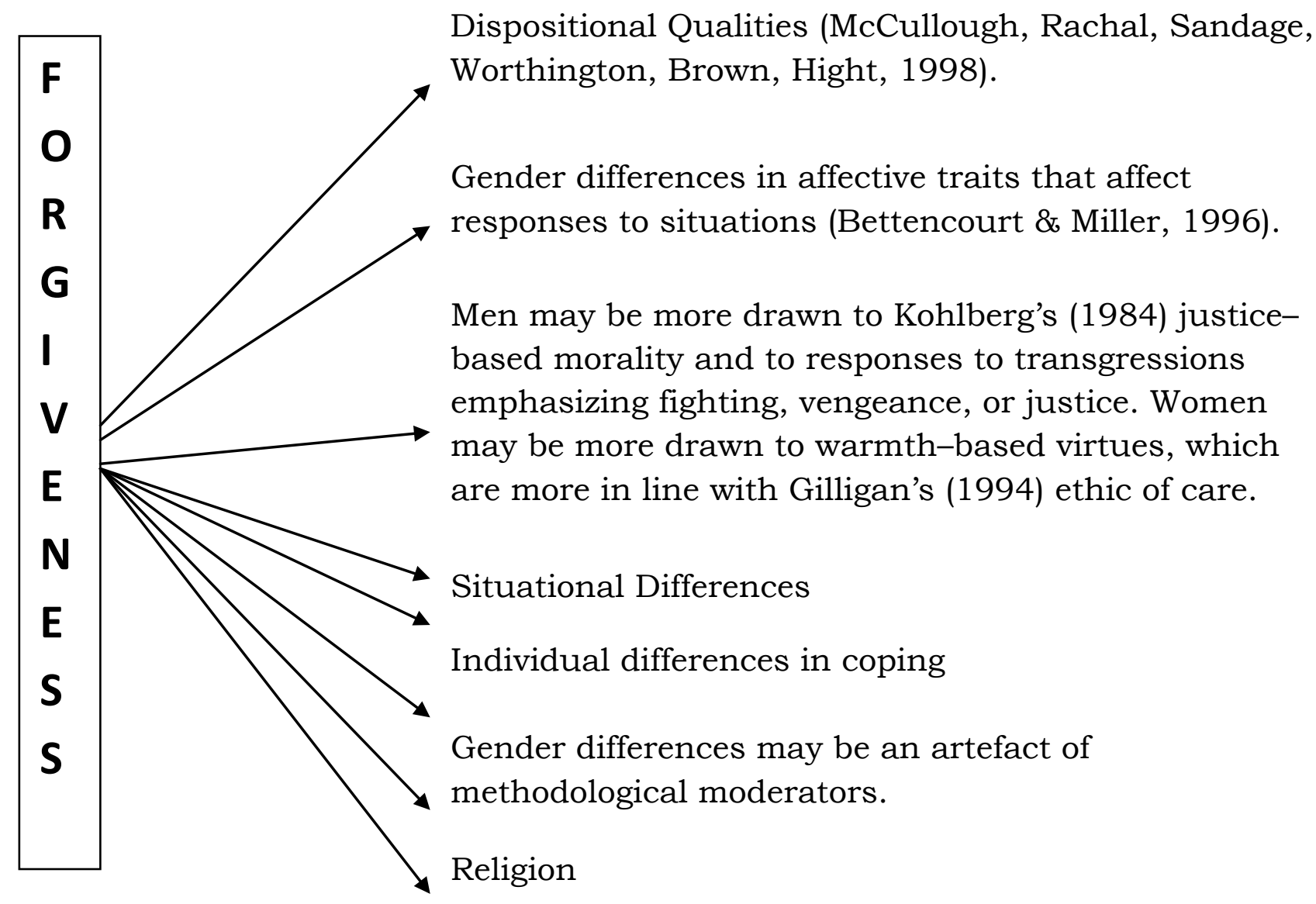

Attachment style (Bartholomew \& Horowitz, 1991).

One of the reasons forgiveness is difficult at workplace is because: first, in the organizational structures there are strict codes of conduct and cultural norms that do not overlook any deviations from the desired behavior by the institution. Doing so, would mean that such acts are condoned and it may set a bad example for other employees at work. Second, it depends on the personality of the workers. If the individuals take forgiveness as a chance to repeat their behaviors it might harm the working of the organization. Thus, it is not widely practiced. But 


\section{A Comparative Study of Psychological Distress, Life Satisfaction, Forgiveness and Happiness in Private Sector It Professionals: An Exploratory Study}

there are committed workers, who value their work and deserve forgiveness for the unintentional blunders in their operations while at the workplace. Thus, if we indulge into acts of forgiveness at workplace it will help the workers grow and learn because it will provide them with a harmonious working environment with a sense of belongingness. Also, it is perceived by good leaders that the cost of not forgiving is greater than the cost of forgiving.

\section{METHODOLOGY}

In this study an attempt has been made to compare the level of the Psychological Distress, Life Satisfaction, Forgiveness, and Happiness on the basis of gender in Private Sector IT Professional. Also an additional aim was established to study the relationship, if any, among the variables of the study (viz., Psychological Distress, Life Satisfaction, Forgiveness, and Happiness)

\section{Hypotheses}

- There will be significant difference between the levels of psychological distress, forgiveness, happiness and life satisfaction in males and females of Private Sector IT Companies.

- There will be a significant relationship between Psychological Distress, Life Satisfaction, Forgiveness and Happiness.

To fulfil the above aim and objective a two group research design was employed.

\section{Participants}

The sample consisted of 60 private sector IT professionals (30 male and 30 females) from Jaipur city. The Participants who gave their consent to participate in the study were included in the sample. in order to test the hypotheses; data was collected with the help of questionnaires which were administered in random order.

\section{Measures}

- $\quad$ General Health Questionnaire (GHQ-12) (Goldberg \& Williams, 1988):

The 12-item General Health Questionnaire (GHQ-12) is used routinely as a one-dimensional measure of psychological morbidity. Many factor-analytic studies have reported that the GHQ12 has two or three dimensions, threatening its validity. It is possible that these 'dimensions' are the result of the wording of the GHQ-12, namely its division into positively phrased (PP) and negatively phrased (NP) statements about mood states. Such 'method effects' introduce response bias which should be taken into account when deriving and interpreting factors.

- $\quad$ The Satisfaction with Life Scale (SWLS) (Diener et al., 1985):

A 5-item scale designed to measure global cognitive judgments of one's life satisfaction (not a measure of either positive or negative affect). Participants indicate how much they agree or 


\section{A Comparative Study of Psychological Distress, Life Satisfaction, Forgiveness and Happiness in Private Sector It Professionals: An Exploratory Study}

disagree with each of the 5 items using a 7-point scale that ranges from 7 (strongly agree) to 1 (strongly disagree).

The Satisfaction with Life Scale (SWLS) was developed to assess satisfaction with the respondent's life as a whole. The scale does not assess satisfaction with life domains such as health or finances but allows subjects to integrate and weight these domains in whatever way they choose. It shows good convergent validity with other scales and with other types of assessments of subjective well-being. Life satisfaction as assessed by the SWLS shows a degree of temporal stability (e.g., .54 for 4 years), yet the SWLS has shown sufficient sensitivity to be potentially valuable to detect change in life satisfaction during the course of clinical intervention. Further, the scale shows discriminant validity from emotional well-being measures. The SWLS is recommended as a complement to scales that focus on psychopathology or emotional wellbeing because it assesses an individuals' conscious evaluative judgment of his or her life by using the person's own criteria.

- $\quad$ Heartland Forgiveness Scale (Snyder, Thompson \& Hoffman, 2005):

The Heartland Forgiveness Scale (HFS), a self-report measure of dispositional forgiveness (with subscales to assess forgiveness of self, others, and situations) was developed and demonstrated good psychometric properties. Forgiveness correlated positively with cognitive flexibility, positive affect, and distraction; it correlated negatively with rumination, vengeance, and hostility. Forgiveness predicted four components of psychological well-being (anger, anxiety, depression, and satisfaction with life); forgiveness of situations accounted for unique variance in these components of psychological well-being. Forgiveness and hostility demonstrated equivalent, inverse associations with relationship duration, and forgiveness accounted for unique variance in relationship satisfaction, even when controlling for trust. Forgiveness level correlated positively with decreased negativity in statements written about transgressions in the present versus the past tense.

- $\quad$ Oxford Happiness Questionnaire (Argyle \& Hills, 1989):

The Oxford Happiness Questionnaire is a 29-item inventory multiple choice instrument which provides a general measure of happiness. Argyle \& Hills proposed that happiness depends on frequency and positive affect or joy, high level of satisfaction over a period of time, and the absence of negative feeling such as depression or anxiety.

Argyle, Martin \& Crossland (1989) reported an internal reliability of .90 using Cronbach’s alpha and a 7-week test-retest reliability of .78. construct validity was developed based on three hypothsised components of happiness: the correlation between the Oxford Happiness Inventroy and Positive Affect Scale as measured by the Bradburn Balanced Affect Scale (Bradburn, 1969) was .32. the correlation between the Oxford Happiness Inventory and Argyle's Life Satisfaction Index (Argyle,1987) was .57, and the correlation between the Oxford Happiness Inventory and 


\section{A Comparative Study of Psychological Distress, Life Satisfaction, Forgiveness and Happiness in Private Sector It Professionals: An Exploratory Study}

Beck Depression Inventory (Beck,1978) was -.52. Each item of this scale contains six options constructed to reflect incremental steps defined as: Strongly Disagree to Strongly Agree. The respondents will be asked to pick out the one option in each statement which best describes the way you have been feeling over the past week including today.

\section{RESULT}

Table 1: Mean, SDs and t-value of GHQ, Forgiveness, Life Satisfaction, and Happiness for Male and Female Private Sector IT Professionals

\begin{tabular}{|c|c|c|c|c|}
\hline & & MEAN & \begin{tabular}{|l|} 
SDs \\
\end{tabular} & t-value \\
\hline \multirow[t]{2}{*}{ GHQ } & Male & 10.70 & 7.028 & \multirow[t]{2}{*}{$2.331 *$} \\
\hline & Female & 7.23 & \begin{tabular}{|l|}
4.116 \\
\end{tabular} & \\
\hline \multirow{2}{*}{$\begin{array}{l}\text { FORGIVENESS } \\
\text { (SELF) }\end{array}$} & Male & 27.63 & \begin{tabular}{|l|}
6.349 \\
\end{tabular} & \multirow[t]{2}{*}{0.081} \\
\hline & Female & 27.50 & \begin{tabular}{|l|l}
6.345 \\
\end{tabular} & \\
\hline \multirow{2}{*}{$\begin{array}{l}\text { FORGIVENESS } \\
\text { (OTHERS) } \\
\end{array}$} & Male & 26.67 & 6.640 & \multirow[t]{2}{*}{0.456} \\
\hline & Female & 25.97 & 5.169 & \\
\hline \multirow{2}{*}{$\begin{array}{l}\text { FORGIVENESS } \\
\text { (SITUATIONS) }\end{array}$} & Male & 26.53 & 6.285 & \multirow[t]{2}{*}{0.249} \\
\hline & Female & 26.93 & 6.170 & \\
\hline \multirow[t]{2}{*}{ FORGIVENESS } & Male & 80.83 & 15.389 & \multirow[t]{2}{*}{0.108} \\
\hline & Female & 80.40 & 15.743 & \\
\hline \multirow{2}{*}{$\begin{array}{l}\text { LIFE } \\
\text { SATISFACTION }\end{array}$} & Male & 23.17 & 6.513 & \multirow[t]{2}{*}{1.673} \\
\hline & Female & 25.70 & 5.134 & \\
\hline \multirow[t]{2}{*}{ HAPPINESS } & Male & 126.33 & 19.329 & \multirow[t]{2}{*}{0.627} \\
\hline & Female & 129.27 & \begin{tabular}{|l|}
16.821 \\
\end{tabular} & \\
\hline
\end{tabular}

* Correlation is significant at 0.05 levels

Table1 gives an account of results showing Mean and SDs of Psychological Distress, Life Satisfaction, Forgiveness and Happiness of Male and Female IT Professionals along with Mean differences (t-value). It is clear from the table above that there is a significant difference between male (Mean 10.70; SD 7.028) and female (Mean 7.23;SD 4.116) on psychological distress scores $(\mathrm{t}$-value $=2.331 ; \mathrm{p}<.05)$. There is no significant difference between the two genders on Forgiveness (t-value $=0.108 ; \mathrm{p}>.05$ ), Life Satisfaction (t-value=1.673; $\mathrm{p}>.05$ ), and Happiness (tvalue $=0.627 ; \mathrm{p}>.05)$. 
A Comparative Study of Psychological Distress, Life Satisfaction, Forgiveness and Happiness in Private Sector It Professionals: An Exploratory Study

Table 2: Correlations between Psychological Distress, Life Satisfaction, Forgiveness, and Happiness $(N=60)$

\begin{tabular}{|c|c|c|c|c|c|c|c|}
\hline & 䍃 & 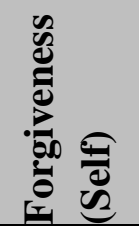 & 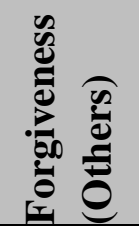 & 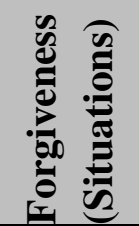 & 莕 & & 号 \\
\hline GHQ & 1 & & & & & & \\
\hline $\begin{array}{l}\text { Forgiveness } \\
\text { (Self) }\end{array}$ & .077 & 1 & & & & & \\
\hline $\begin{array}{l}\text { Forgiveness } \\
\text { (Others) }\end{array}$ & .022 & $.499 * *$ & 1 & & & & \\
\hline $\begin{array}{l}\text { Forgiveness } \\
\text { (Situations) }\end{array}$ & -.107 & $.562 * *$ & $.612^{* *}$ & 1 & & & \\
\hline Forgiveness & -.003 & $.824 * *$ & $.831^{* *}$ & $.864 * *$ & 1 & & \\
\hline Life Satisfaction & $-.289 *$ & -.056 & -.093 & .025 & -.049 & 1 & \\
\hline Happiness & $-.401 * *$ & -.083 & -.136 & .051 & -.065 & $.275^{*}$ & 1 \\
\hline
\end{tabular}

** Correlation is significant at 0.01 levels

* Correlation is significant at 0.05 levels

Table 2 shows correlation among Psychological Distress, Life Satisfaction, Forgiveness and Happiness. As expected, most of the variables are significantly correlated with each other. There is a significant negative correlation between Psychological Distress and Life Satisfaction $(\mathrm{r}=-$ .289; $\mathrm{p}<.05)$, and Happiness ( $\mathrm{r}=-.401 ; \mathrm{p}<.01)$. It is also evident that there is a significant positive correlation between Life Satisfaction and Happiness $(r=.275 ; \mathrm{p}<.05)$.

However, Psychological Distress is not significantly correlated to Forgiveness (Self, Others and Situations) ( $\mathrm{r}=-.003(.077, .022,-.107)$ respectively; $\mathrm{p}>0.05)$. Forgiveness (Self, Others and Situations) is not correlated to Life Satisfaction ( $r=-.49$ (-.056, -.093, .025 respectively); $\mathrm{p}>.05)$ and Happiness ( $r=-.065(-.083,-.136, .051$ respectively); $\mathrm{p}>.05)$

\section{DISCUSSION}

All the variables of the present study are vital for investigating the optimal functioning of the individuals in work environment based on their gender differences. The aim of this research was to compare the levels of Psychological Distress, Life Satisfaction, Forgiveness and Happiness in male and female IT Professionals.

It is evident from the result table that there is a significant difference between male and female private sector IT professionals on Psychological Distress (GHQ). The results contradict the 


\section{A Comparative Study of Psychological Distress, Life Satisfaction, Forgiveness and Happiness in Private Sector It Professionals: An Exploratory Study}

researcher's expectations, as the level of distress is higher in males as compared to females. The reasons might be because of personal, social, cultural values or because of social rules regarding acceptable masculine behavior(Meth et al., 1990; Cochran \& Rabinowtiz, 2000; Grant \& Potenza, 2007; Aldoory et al., 2008). Men have traditionally been taught to focus on their careers as a large part of their identity and success (Cochran \& Rabinowski, 2000; Grant \& Potenza, 2007; Wexler, 2009). These social norms combined with the changing roles of men, not just as the main provider but also sharing the load as caregiver and housekeeper, have potentially had an effect on work-life balance for men (Aumman et al., 2011). In men, work-life imbalance can affect aspects of their psychological well-being such as self-control, life satisfaction, and anxiety (Burke, 2000; Frone, 2000). Because of lack of balance in the personal and professional life and unexpected social norms for the male behaviour can lead to more psychological distress among the male population as compared to the females.

According to Powell and Greenhaus (2006), women may have difficulties maintaining their own work-life balance, especially in work settings where they do not receive much formal support from their employer. But it has been observed that women get a fair share of support and understanding from their employers in Indian Scenario as they are considered weaker sex. Support from the employers can vary on boss-to-boss basis. They can provide the women with greater schedule flexibility, child-care services, flexible spending accounts and reduction in working hours, thus restoring their work-life balance and reducing their psychological distress. Since more initiatives have been taken to improve the working conditions for females, they are likely to suffer from decreased level of psychological stress.

There is no significant difference between the male and female private sector IT professional on life satisfaction, happiness and measures of forgiveness. This might be because life satisfaction, happiness and forgiveness originate between males and females due to role conflicts experienced by them in different ways. Women struggle with the dual role conflicts within their personal and professional domains, which burdens them with tremendous pressure to justify to all their responsibilities. Men on the other hand suffer from unexpected male behaviour societal norms which cause fluctuations in their level of subjective well-being.

As observed, there was no significant difference in the levels of Life Satisfaction between the genders. The reason might be that the, greater the gender equality within a culture (i.e., freedom to make reproductive choices, equal pay, equal value under the law, equal opportunity to education and achievement), the individuals report greater life satisfaction (Sousa and Lyubomirsky 2000). Bjornskov et al. (2007) reported that women have increased levels of satisfaction and overall positive evaluations of their life because of political and cultural equality and independence for the past 20 years. This could be seen as the possible reason for equal experience of life satisfaction. As the standard and the way females are treated nowadays is more towards equal privileges and rights.

(c) The International Journal of Indian Psychology, ISSN 2348-5396 (e)| ISSN: 2349-3429 (p) | 59 


\section{A Comparative Study of Psychological Distress, Life Satisfaction, Forgiveness and Happiness in Private Sector It Professionals: An Exploratory Study}

Argyle (1987) concludes that there is little gender difference in satisfaction with life as a whole. Mrocek and Kolarz (1998) established that "women appear to be less happy, and this seems to persist across all age groups”. In contrast, Nolen-Hoeksema and Rusting (1999) report that “a number of studies have found that women report experiencing greater happiness and more intense positive emotions than men” and the results of the present study reports no difference in the experience of happiness in males and females.

These mixed results might be because of the reasons that the sample consist of adulthood population. It was reported that women experience positive affect at the younger age than men, which becomes differing after retirement and differences between genders differ at various point of time in their life Rousseau (2009).

Further the results also indicate no difference between the genders on the construct of Forgiveness. Sinceorganisational structures discourage the conduct of forgiveness and compassion within their strict professional operations. It can be safely concluded that even though women are more empathetic than men still there will be no difference in the practice of forgiveness between the genders (Worthington et al., 2000).Macaskill et al. (2002) also did not find any significant gender differences in the participant's forgiveness towards self or others. The study reported that women experience higher levels of empathy than men, but in either type of forgiveness, no gender difference was observed.

It was unexpected to observe no significant difference on Life Satisfaction, Happiness, and Forgiveness in both the groups (male and female) despite difference in the level of psychological distress experienced by them as it was hypothesized that the level of psychological distress would in some way or the other affect the level of Life Satisfaction, forgiveness and happiness experienced by an individual. A further analysis of data, to examine the relationship among the variables of study (psychological distress, life satisfaction, forgiveness, and happiness) correlation analysis was employed.

The results indicate a negative relationship between Psychological Distress and Life Satisfaction, i.e., if the unpleasant and negative emotions are present in the individuals (Psychological Distress), then their overall positive evaluation of their life considerably decreases (life satisfaction) another reason could be the incongruence between the expectations and outcomes which lead to psychological distress and that further affects the level of satisfaction one has in their life. Similar results were found in a study conducted by Abdulghani et al (2011) showing a significant correlation between stress and mental illness among university students and their life satisfaction. Thus, negative and self-defeating cognitions are unconditional and over-generalised and subsequently affect individual perception of one's whole life (Sanders \& Wills, 2005). 


\section{A Comparative Study of Psychological Distress, Life Satisfaction, Forgiveness and Happiness in Private Sector It Professionals: An Exploratory Study}

Also there was a negative relationship between Psychological distress and Happiness. High levels of unconstructive perceptions and affect does not seem to leave much space for positive and joyful experiences. Thus, heightened levels of distress and anxiety can reduce happiness and experience of enjoyment among the individuals as quoted by Csikszentmihalyi (1988, 1997, 2002).

The correlation matrix also demonstrated a significant positive correlation between Life Satisfaction and Happiness. Both the constructs are an essential part of Subjective well-being which is refers as the different evaluations people make of their lives overall in various domains (Diener, 1984,2009; Diener et al., 1999;Diener and Suh,1997;Kanheman, 1999; Kanheman and Krueger, 2006). It includes both a cognitive and affective component (Arhaud-Day et al., 2005; Diener et al., 1985). The cognitive component consists of individual's judgements of their life satisfaction, whereas the affective component consists of the moods and emotions they experience like, joy and happiness. Which clearly indicated why both the constructs (Life Satisfaction and Happiness) are highly positively correlated.

\section{CONCLUSION}

It can be concluded from the present study that through developing training and intervention programs focused towards enhancing the level of life satisfaction, forgiveness and happiness, the level of psychological distress can be reduced and work-life balance can be restored, i.e., if the levels of happiness, forgiveness and life satisfaction is increased, psychological distress among the workers will be reduced.

\section{REFERENCES}

Abdulghani, H.M., Alkanhal, A.A., Mahmoud, E.S., Oonnamperuma, G.G., \&Alfaris, E. A. (2011). Stress and its effects on medical students: a crosssectional study at a college of medicine in Saudi Arabia. Journal of Health Population and Nutrition, 29(5), 516-522

Aldoory, L., Jiang, H., Toth, E. L., \& Sha, B-L. (2008). Is it still just a women's issue? A study of work-life balance among men and women in public relations. Public Relations Journal, 2(4).

American Psychological Association. (2004). Public policy, work and families: The Report of the APA Presidential Initiative on Work and Families. Retrieved from http://www.apa.org

Argyle, M. (1987). The psychology of happiness. London: Routledge.

Argyle, M., Martin, M., \&Crossland, J. (1989). Happiness as a function of personality and social encounters. In J. P. Forgas\& J. M. Innes (Eds), Recent advances in social psychology: An international perspective, (pp. 189-203). North Holland: Elsevier Science Publishers.

Arthaud-Day, M.L., Rode, J.C., Mooney, C.H., \& Near, J.P. (2005). The subjective well-being construct: a test of its convergent, discriminant, and Factorial validity. Social Indicators Research, 74, 445-476

Aumann, K., Galinsky, E., Matos, K. (2011). The new male mystique. New York, NY: Families and Work Institute. 
Barnett, R. C. \& Baruch, G. K. (1985).Women’s involvement in multiple roles and psychological distress. J PersSocPsychol 49:135-145

Bartholomew, K., \& Horowitz, L. M. (1991). Attachment styles among young adults:Atest of a four-category model. Journal of Personality and Social Psychology, 61, 226-244.

Beck, A.T. (1978). The depression inventory. Philadelphia: Center for Cognitive Therapy.

Bettencourt, B. A., \& Miller, N. (1996). Gender differences in aggression as a function of provocation: A meta-analysis. Psychological Bulletin, 119, 422-447.

Bharat, S. (2003). "Women, work, and family in urban India, Towards new families?” in J. W. Berry, R. C. Mishra, and R. C. Tripathi ed., Psychology in human and social development, Lessons from diverse cultures (pp.155-169). New Delhi, India, Sage.

Bjornskov, C., Dreher, A., \& Fischer, J. (2007). On gender inequality and life satisfaction: Does discrimination matter? (KOF Working papers, No.161, pp. 1-27).

Bradburn N.M.(1969). The structure of psychological well-being. Chicago: Aldine.

Burke, R. (2000). Do managerial men benefit from organizational values supporting workpersonal life balance? Women in Management Review, 15(2), 81

Burke, R. (2000). Do managerial men benefit from organizational values supporting workpersonal life balance? Women in Management Review, 15(2), 81.

Clark, S. C. (2000) Work/family border theory: a new theory of work/family balance. Human Relations, 53(6), 747-770.

Cochran, S.V. \& Rabinowitz, F. E. (2000). Men and depression: clinical and empirical perspectives. San Diego: Academic Press.

Csikszentmihalyi, M. (1988). The flow experience and its significance for human psychology. In M. Csikszentmihalyi, \& I.S. Csikszentmihalyi (Eds.), Optimal experience: Psychological studies of flow in consciousness (pp. 15-35). Cambridge, United Kingdom: Cambridge University Press. http://dx.doi.org/10.1017/CBO9780511621956.002

Csikszentmihalyi, M. (1997). Finding Flow. The psychology of engagement with everyday life. New York, NY: Perseus Books Group.

Csikszentmihalyi, M. (2002). Flow:The classic work on how to achieve happiness. London, United Kingdom: Rider.

Darcy, C., McCarthy, A., Hill, J., \& Grady, G. (2012) Work-life balance: One size fits all? An exploratory analysis of differential effects of career stage. European Management Journal, 30 (2), 111-120.

Diener, E., Emmons, R. A., Larsen, R. J. \& Griffin, S. (1985). The Satisfaction with Life Scale. Journal of Personality Assessment, 49, 71-75.

Diener, E., Emmons, R. A., Larsen, R. J., \& Griffin, S. (1985). The Satisfaction with Life Scale. Journal of Personality Assessment, 49, 71-75.

Diener, Ed (1984). 'Subjective Well-Being.’ Psychological Bulletin, 95 (3), 542-575.

Diener, Ed and Eunkook M. Suh (1997). 'Measuring quality of life: Economic, social and subjective indicators.’ Social Indicators Research, 40 (1-2), 189-216.

Diener, Ed, Eunkook M. Suh, Robert E. Lucas and Heidi L. Smith (1999). 'Subjective WellBeing: Three Decades of Progress.’ Psychological Bulletin, 125 (2), 276-302.

Emslie, C. \& Hunt, K. (2009). 'Live to Work' or 'Work to Live'? A qualitative study of gender and work-life balance among men and women in mid life. Gender Work and Organization, 16(1). 
A Comparative Study of Psychological Distress, Life Satisfaction, Forgiveness and Happiness in Private Sector It Professionals: An Exploratory Study

Frone, M. R. (2000). Work-family conflict and employee psychiatric disorders: The national comorbidity survey. Journal of Applied Psychology, 85(6), 888-895.

doi:10.1037/0021-9010.85.6.888

Gilligan, C. (1994). In a different voice: Women's conceptions of self and of morality. New York: Garland Publishing.

Golderberg, D. \& Williams, P. (1988). A user's guide to the General Health Questionnaire. Windsor, UK, NFER-Nelson.

Grant, J. E. \& Potenza, M. N. (2007). Textbook of men's mental health (1st ed). American Psychiatric Pub, Washington, DC

Greenhaus, J. H. \& Powell, G. N. (2006). When work and family are allies: A theory of workfamily enrichment. Academy of Management Review, 31(1), 72-92.

Halrynjo, S. (2009). Men's work-life conflict: Career, care and self-realization: Patterns of priveileges and dilemmas. Gender, Work, and Organization, 16(1), 98-125.

Harris, A. H. S.,\&Thoresen, C. E. (2005). Forgiveness, unforgiveness, health, and disease. In E. L. Worthington, Jr. (Ed.), Handbook of forgiveness (pp. 321-333). New York: BrunnerRoutledge.

Hills, P. \& Argyle, M. (1989). The Oxford Happiness Questionnaire: a compact scale for the measurement of psychological well-being. Personality and Individual Differences, 33, 1073-1082.

Hochschild, A. (1997). When work becomes home and home becomes work. California Management Review, 39(4), 79-97.

Introduction to the work life. (2016, April 5). Retrieved from: http://realsociology.edublogs.org/2012/03/31/what-percentage-of-your-life-will-youspend-at-work/

Kahneman, D. \& Krueger, A. B. (2006) Developments in the measurement of subjective wellbeing. Journal of Economic Perspectives, 20(1), 3-24.

Kahneman, D. (1999). Objective happiness. In D. Kahneman, E. Diener\& N. Schwarz (Eds.). Well-being: The foundations of hedonic psychology (pp. 3-25). New York: Russell Sage Foundation.

Kalliath, T., \&Brough, P. (2008). Work-life balance: A review of the meaning of the balance construct. Journal of Management \& Organization, 14(3), 323-327. doi:10.5172/jmo.837.14.3.323

Karasek, R. A. (1979). "Job demands, job decision latitude, and mental strain: Implication for job redesign." Administrative Science Quarterly, 24, 285-309.

Karasek, R.A. \& Theorell, T. (1990). Healthy work: stress, productivity, and the reconstruction of the working life. New York: Basic Books.

Karremans, J. C., Van Lange, P. A. M., Ouwerkerk, J. W.,\& Kluwer, E. S. (2003). When forgiving enhances psychological well-being: The role of interpersonal commitment. Journal of Personality and Social Psychology, 84, 1011-1026.

Kirmayer, L.J. (1989). "Cultural variations in the response to psychiatric disorders and psychological distress." Social Science and Medicine 29, 327-339.

Kleinman, A. (1991). Rethinking Psychiatry. From Cultural Category to Personal Experience. New York: The Free Press.

Kohlberg, L. (1984). Essays on moral development: The psychology of moral development (Vol 2). New York: Harper. 


\section{A Comparative Study of Psychological Distress, Life Satisfaction, Forgiveness and Happiness in Private Sector It Professionals: An Exploratory Study}

Komarraju, M. (1997). “The work-family interface in India” (pp. 104-114). In Parasuraman, S. \&Greenhaus, J. H. Eds., Integrating work and family, Challenges for a changing world. Westport, CT, Quorum Books.

Lyubomirsky, S., King, L., \&Diener, E. (2005). The benefits of frequent positive affect: Does happiness lead to success? Psychological Bulletin, 131, 803-855.

Macaskill, A., Maltby, J., \& Day, L. (2002). Forgiveness of self and others and emotional empathy. The Journal of Social Psychology, 142, 663-665.

Marchand, A., A. Demers \& Durand, P. (2005). "Does work really cause distress? The contribution of occupational structure and work organization to the experience of psychological distress." Social Science and Medicine, 60, 1-14.

McCullough, M. E., Rachal, K. C., Sandage, S. J., Worthington, E. L., Jr., Brown, S. W., \&Hight, T. L. (1998). Interpersonal forgiving in close relationships II: Theoretical elaboration and measurement. Journal of Personality and Social Psychology, 73, 321336.

Meth, R.L., Pasick, R.S., Gordon, B., Allen, J., Feldman, L.B., \& Gordon, S. (1990). Men in Therapy. New York: The Guilford Press.

Mirowsky, J. \& Ross, C. E. (2002). "Selecting outcomes for the sociology of mental health: Issues of measurement and dimensionality." Journal of Health and Social Behavior, 43, 152-170.

Mrozek, D. K. and Kolarz, C. M. (1998). The effect of age on positive and negative affect: A developmental perspective on happiness. Journal of Personality and Social Psychology75(5), 1333-1349.

Myers, D.G., \&Diener, E. (1995). Who Is Happy? Psychological Science, 6(1), 1017.

Nolen-Hoeksema, S. \& Rusting, C.L. (1999). Gender differences in well-being. In D. Kahneman, E. Diener, \& N. Schwarz (Eds.), Well-being: the foundations of hedonic psychology (pp. 330-350). New York: Russell Sage Foundation

Phillips, D. (2006). Quality of life and sustainability. International Journal of Environmental, Cultural, Economic and Social Sustainability, 2(2), 103-112.

Rajadhyaksha, U. \& Bhatnagar, D. (2000). "Life role salience: A study of dual career couples in the Indian context”. Human Relations,53, 489-511.

Rousseau, J.B., (2009). Happiness and income inequality. Mimeo.

Sanders, D., \& Wills, F. (2005). Cognitive therapy: An introduction. $\left(2^{\text {nd }}\right.$ ed.). London: Sage.

Sekaran, U. (1992). "Middle-class dual-earner families and their support systems in urban India" (pp. 46-61). In Lewis, S., Izraeli, D. N. \&Hootsmans, H., ed., Dual-earner families, International perspectives. Newbury Park, CA, Sage.

Shin, D., \& Johnson, D. (1978). Avowed Happiness as an Overall Assessment of the Quality of Life. Social Indicators Research, 5, 475-492. http://dx.doi.org/10.1007/BF00352944

Siegrist, J. (1996). "Adverse health effects of high-effort/low-reward conditions." Journal of Occupational Health Psychology, 1, 27-41.

Sousa, L. \&Lyubomirsky, S. (2000). Life Satisfaction. In: J Wore (Ed.): Encyclopaedia of Women and Gender. Sex Similarities and Differences and the Impact of Society on Gender(pp. 667-676). New Jersey, Prentice Hall.

Sunita Malhotra \&SapnaSachdeva, "Social Roles and Role Conflict: An Interprofessional Study among Women", Journal of the Indian Academy of Applied Psychology, January - July 2005, Vol. 31, No.1-2, 37-42. 


\section{A Comparative Study of Psychological Distress, Life Satisfaction, Forgiveness and Happiness in Private Sector It Professionals: An Exploratory Study}

Ten Brummelhuis, L. L., \& van der Lippe, T. (2010). Effective work-life balance support for various household structures. Human Resource Management, 49(2), 173-193.

Thompson, L.Y., Snyder, C. R., \& Hoffman, L. (2005). "Heartland Forgiveness Scale". Faculty Publications, Department of Psychology. Paper 452.

Toussaint, L., \& Webb, J. R. (2005). Theoretical and empirical connections between forgiveness, mental health, and well-being. In E. L. Worthington (Ed.), Handbook of forgiveness (pp. 349-362). New York: Brunner- Routledge.

Wexler, L. (2009). The importance of identity, history and culture in the wellbeing of Indigenous youth. Journal of the History of Childhood and Youth, 2(2), 267-76.

Worthington, E. L., Jr. (Ed.). (2005). Handbook of forgiveness. New York: Brunner- Routledge.

Worthington, E. L., Jr., Witvliet, C. V. O., Pietrini, P., \&. Miller, A. J. (2007). Forgiveness, health, and well-being: A review of evidence for emotional versus decisional forgiveness, dispositional forgivingness, and reduced unforgiveness. Journal of Behavioral Medicine, 30.

Worthington, E. L., Sandage, S. J., \& Berry, J. W. (2000). Group interventions to promote forgiveness: What researchers and clinicians ought to know (pp. 228-253). In: McCullough ME, Pargament KI, Thoresen CE, editors. Forgiveness: Theory, research, and practice. New York: Guilford.

How to cite this article: M Sharma, D Garg (2016), A Comparative Study of Psychological Distress, Life Satisfaction, Forgiveness and Happiness in Private Sector It Professionals: An Exploratory Study, International Journal of Indian Psychology, Volume 3, Issue 3, No. 10, DIP: 18.01.178/20160303, ISBN: 978-1-365-19879-3 